\title{
Research on the multi-level intake water temperature effect of the Yalong River Jinping-I hydropower project
}

\author{
WU ShiYong $^{1 *}$, CAO Wei ${ }^{1}$, WANG HongMei ${ }^{1}$, SUN ShuangKe ${ }^{2}$ \& CHEN QiuWen ${ }^{3}$ \\ ${ }^{1}$ Ertan Hydropower Development Company, Ltd., Chengdu 610051, China; \\ ${ }^{2}$ China Institute of Water Resources and Hydropower Research, Beijing 100038, China; \\ ${ }^{3}$ Research Center for Eco-Environmental Sciences, Chinese Academy of Sciences, Beijing 100085, China
}

Received July 5, 2011; accepted October 12, 2011; published online November 18, 2011

\begin{abstract}
Based on the discussion of the multi-level intake application status of high dam reservoir, this paper takes the Jinping-I hydropower project reservoir in the Yalong River as an example, which is shaped by the highest $305 \mathrm{~m}$ high arch dam, and carries out the forecasting research on the reservoir temperature by numerical simulation and physical model testing. This paper studies the intake effect of withdrawing the surface warm water by the stoplog gates inlets and verifies the reliability of the mathematical model by comparative analysis. The results show that for a high dam hydropower station, taking the appropriate multi-level intake measure can withdraw the surface warm water in the spawning season and provide a favorable environment for the fish reproduction. Innovative technical ideas and implementation scheme are adopted in this research. It can provide technical reference for the solutions of similar problems in the future and it also has important engineering significance on the research of water temperature in large deep reservoirs.
\end{abstract}

water temperature, multi-level intake, Jinping-I hydropower project

Citation: Wu S Y, Cao W, Wang H M, et al. Research on the multi-level intake water temperature effect of the Yalong River Jinping-I hydropower project. Sci China Tech Sci, 2011, 54(Suppl. 1): 125-132, doi: 10.1007/s11431-011-4628-1

\section{Introduction}

A large built reservoir with excellent regulation capability would bring about some adverse impact on water environment [1], ecological environment [2], etc. Because of the water storage function and the energy exchange between the water and the atmosphere, the reservoir presents different degree thermal stratification along the depth direction, which makes the temperature of discharged water lower than the natural situation in spring and summer, and higher than the natural situation in winter. Changes of the water temperature distribution in the natural river course, especially in the spawning seasons (March to June every year)

*Corresponding author (email: wushiyong@ehdc.com.cn) during which the released cold water will bring about adverse effect on the living and reproduction of the fish in the downstream, would cause reduction or even extinction of some fish species. As an efficient engineering measure adopted to control the discharged water temperature, the multi-level intake technique [3] catches widespread attention at home and abroad. In America, some water inlets in hydropower station have been rebuilt to set the multi-level intake installations. The Hungry Horse Dam [4] built in 1948 has achieved the multi-level intake function by utilizing the existing trash racks and mounting 3 free lifting independent gates in the front of the inlets. The operation data shows that the multi-level intake system can effectively raise the downstream water temperature and reduce the intense temperature fluctuating degree in a short term. Shasta Dam [5, 6] adopted a water temperature control structure for 
multi-level intake by installing a steel mega-frame similar to louver in the inlet. The leading edge of each inlet unit is provided with three sets of hoisting equipment and trash racks, so as to allow every pressure pipeline to withdraw water from inlets at high, middle and low elevations, and to achieve the multi-level intake function. The running results show that the multi-level intake facilities have greatly improved the thermal stratification structure of reservoir, the discharged water almost can meet requirements for river water temperature at all times. Multi-level intake technology has been researched and applied to a certain degree in China. Guizhou Guangzhao Hydropower Station [7] adopts the multi-level intake program of 6 holes stoplog gates. A three-dimensional numerical model predication of water temperature shows that the annual mean temperature of discharged water in the reservoir is increased by adopting the stoplog gates water intake scheme, and the discharged water temperature is $3.1^{\circ} \mathrm{C}$ higher than that of the single-level intake scheme. Yunnan Nuozhadu Hydropower Station adopts the multi-level intake program of 9 holes stoplog gates. According to monthly water temperature distribution of Nuozhadu reservoir in a normal flow year. Some scholars in China [8] carried out experimental study of discharged water temperature when running stoplog gates in compliance with the design scheme; it is confirmed that the discharged water temperature is greatly increased by adopting multi-level inlets in a hydropower station compared to the traditional single-level inlet. The research above shows that multi-level intake technology for hydropower station is gradually popularized and applied to protecting ecological environment in China. But there are few systematic researches concerning about the operating effect of withdrawing the surface warm water.

The Jinping-I hydropower project under construction is a controlling reservoir cascade hydropower station in the midstream and downstream of the Yalong River, and it has a typical multi-level reservoir with annual regulation performance. To alleviate the adverse impact brought by the discharged cold water on the aquatic ecosystem in the downstream, the hydropower project adopts the multi-level intake by setting up the stoplog gates inside the intake tower, so that the surface warm water in the reservoir can be withdrawn in spring, the spawning season, and it is to the benefit of fish living and reproduction.

\section{Porject overview}

The Jinping-I hydropower project is built in the main stream of Yalong River, which locates in the Yanyuan Country and Muli Country, Liangshan Yi Autonomous Prefecture of Sichuan Province, and the station consists of water retaining structure, flood discharging structure, energy dissipation structure and hydraulic power constructions. The water retaining structure is a concrete double-curvature arch dam with a maximal height of $305 \mathrm{~m}$, which is the highest arch dam in the world. The total installed capacity is $6 \times 600 \mathrm{MW}$, normal storage level is $1880 \mathrm{~m}$, dead storage level is 1800 $\mathrm{m}$ and the corresponding storage capacity is 7.76 billion $\mathrm{m}^{3}$. The project started in 2005 , with a plan that the first generating unit will be put into operation in 2012 and the whole station will complete in 2014.

Tower intake arrangement is used in this station. 6 inlets are arranged in a straight line with each supplied by a single machine and single pipe. The elevation of the bottom board of inlets is $1779 \mathrm{~m}$, and the water withdrawn depth is between 21 to $101 \mathrm{~m}$.

\section{Stoplog gates and operating program}

The operating program of the stoplog gates multi-level intake is described as follows. When the water level is above $1842.00 \mathrm{~m}, 3$ gate leaves with a gateway top elevation of $1814 \mathrm{~m}$ are all used to retain water and it is the first layer intake; when the water level is between 1842 and $1828 \mathrm{~m}$, the second and the third gate leaves with a gateway top elevation of $1807 \mathrm{~m}$ are used to retain water and it is the second layer intake; when the water level is between 1828 and $1814 \mathrm{~m}$, the third gate leaf with a gateway top elevation of $1793 \mathrm{~m}$ is used to retain water and it is the third layer intake; else when the water level descends under $1814 \mathrm{~m}$, no gate leaf is used to retain water and it is the fourth layer intake or the single-layer intake. The structural arrangement of the stoplog gates multi-level intake is shown in Figure 1 [9].

\section{Forecasting research of the water tempera- ture process}

A forecasting research [10] on how the multi-level intake program influences the discharged water temperature was conducted to study the effect of withdrawing surface warm water through stoplog gates multi-level intake, and this research also provided the far zone boundary conditions of the thermal stratification for physical model test. Firstly, we combined the water temperature data of the Ertan reservoir with a 2-dimensional water temperature elevation model, of which the width is uniform, to determine and verify the model parameters. Then, we ran a simulation and computed the water temperature distribution in the reservoir of the Jinping-I hydropower project.

\subsection{Forecasting model}

\subsubsection{Basic governing equations}

(1) State equations: Under the condition of ignoring the pressure change influence in density, we can set up the relationship between water temperature and density. 


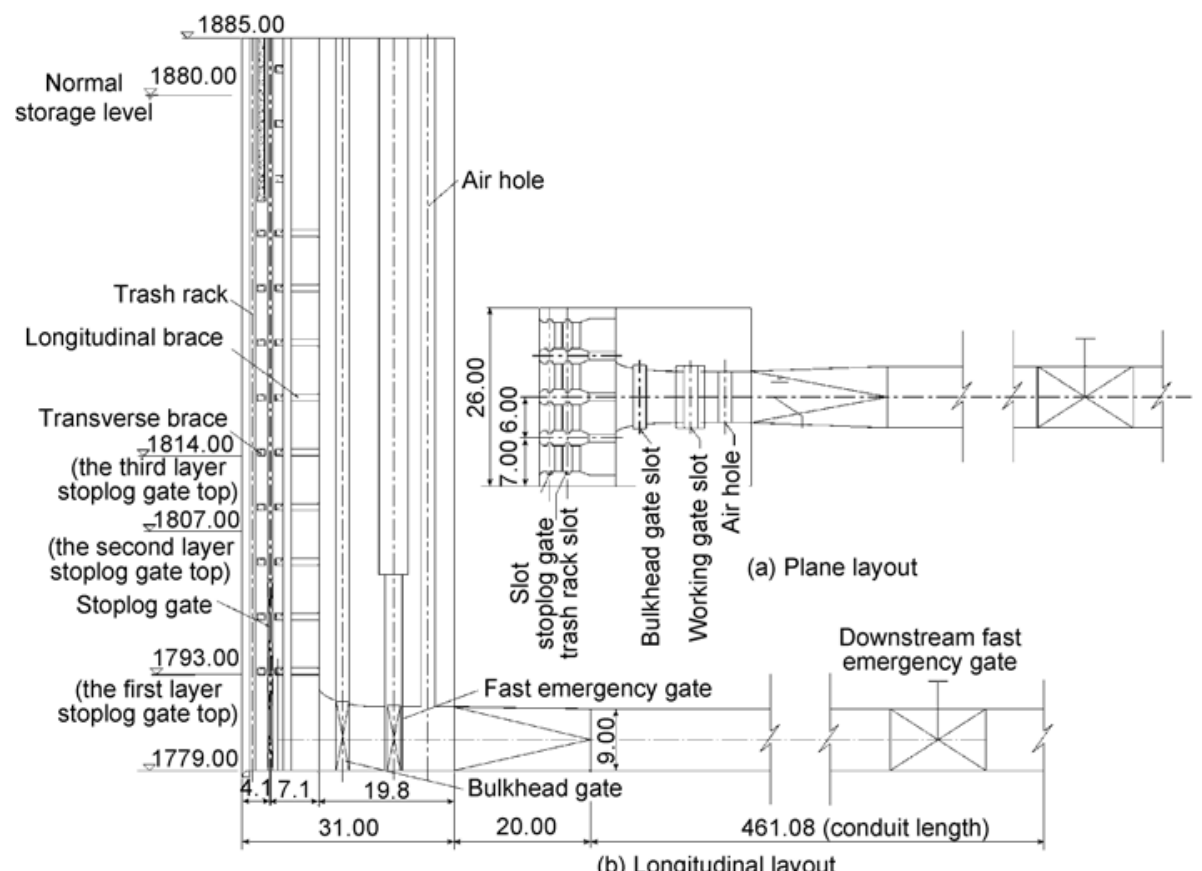

Figure 1 The structural arrangement diagram of the multi-level intake (unit: m) [9].

$$
\frac{\rho-\rho_{s}}{\rho_{s}}=-\beta\left(T-T_{s}\right)=-\beta \Delta T,
$$

where $\beta\left(1 /{ }^{\circ} \mathrm{C}\right)$ is the isobaric expansion coefficient; $\rho\left(\mathrm{kg} / \mathrm{m}^{3}\right)$ is density; $T\left({ }^{\circ} \mathrm{C}\right)$ is temperature; $\rho_{s}, T_{s}$ are the density and temperature under the reference state, respectively. For natural water, the function can be approximated to

$$
\begin{aligned}
\rho= & \left(0.102027692 \times 10^{-2}+0.677737262 \times 10^{-7} \times T\right. \\
& -0.905345843 \times 10^{-8} \times T^{2}+0.864372185 \times 10^{-10} \\
& \times T^{3}-0.642266188 \times 10^{-12} \times T^{4}+0.105164434 \\
& \left.\times 10^{-17} \times T^{7}-0.104868827 \times 10^{-19} \times T^{8}\right) \times 9.8 \times 10^{5} .
\end{aligned}
$$

(2) 2-dimensional hydrodynamic equations: Continuity equation, momentum equation ( $u$ equation and $w$ equation), turbulent kinetic energy $k$, dissipation rate $\varepsilon$ equations, etc. are included. We have considered the influence of the thermal stratification in the gravity item of $w$ equation and the buoyancy item of $k$ equation, so it can be used to simulate the flow field changes under the condition of layered density.

$$
\begin{gathered}
\frac{\partial}{\partial x}(B u)+\frac{\partial}{\partial z}(B w)=0, \\
\frac{\partial}{\partial t}(B u)+u \frac{\partial}{\partial x}(B u)+w \frac{\partial}{\partial z}(B u) \\
=\frac{\partial}{\partial x}\left(B v_{e} \frac{\partial u}{\partial x}\right)+\frac{\partial}{\partial z}\left(B v_{e} \frac{\partial u}{\partial z}\right)-\frac{B}{\rho_{s}} \frac{\partial p}{\partial x}
\end{gathered}
$$

$$
\begin{gathered}
+\frac{\partial}{\partial x}\left(B v_{e} \frac{\partial u}{\partial x}\right)+\frac{\partial}{\partial z}\left(B v_{e} \frac{\partial w}{\partial x}\right) \\
\frac{\partial}{\partial t}(B w)+u \frac{\partial}{\partial x}(B w)+w \frac{\partial}{\partial z}(B w) \\
=\frac{\partial}{\partial x}\left(B v_{e} \frac{\partial w}{\partial x}\right)+\frac{\partial}{\partial z}\left(B v_{e} \frac{\partial w}{\partial z}\right)-\frac{B}{\rho_{s}} \frac{\partial p}{\partial z} \\
-\beta \Delta T g+\frac{\partial}{\partial z}\left(B v_{e} \frac{\partial w}{\partial z}\right)+\frac{\partial}{\partial x}\left(B v_{e} \frac{\partial u}{\partial z}\right) \\
\frac{\partial}{\partial t}(B k)+u \frac{\partial}{\partial x}(B k)+w \frac{\partial}{\partial z}(B k) \\
=\frac{\partial}{\partial x}\left(B \frac{v_{e}}{\sigma_{k}} \frac{\partial k}{\partial x}\right)+\frac{\partial}{\partial z}\left(B \frac{v_{e}}{\sigma_{k}} \frac{\partial k}{\partial z}\right) \\
+B\left(G_{k}+G_{b}-\varepsilon\right), \\
\frac{\partial}{\partial t}(B \varepsilon)+u \frac{\partial}{\partial x}(B \varepsilon)+w \frac{\partial B \varepsilon}{\partial z}=\frac{\partial}{\partial x}\left(B \frac{v_{e}}{\sigma_{\varepsilon}} \frac{\partial \varepsilon}{\partial x}\right) \\
+\frac{\partial}{\partial z}\left(B \frac{v_{e}}{\sigma_{\varepsilon}} \frac{\partial \varepsilon}{\partial z}\right)+B C_{1 \varepsilon} \frac{\varepsilon}{k} G_{k}-B C_{2 \varepsilon} \frac{\varepsilon^{2}}{k},
\end{gathered}
$$

where

$$
\begin{gathered}
G_{k}=v_{e}\left[2\left(\frac{\partial u}{\partial x}\right)^{2}+2\left(\frac{\partial w}{\partial z}\right)^{2}+\left(\frac{\partial u}{\partial z}+\frac{\partial w}{\partial x}\right)^{2}\right] \\
G_{b}=-\beta g \frac{v_{e}}{\sigma_{T}} \frac{\partial T}{\partial z}
\end{gathered}
$$

is the buoyancy item. The buoyancy item is an important 
factor for the reservoir to keep layers stable, because it can restrain the generation of turbulent kinetic energy and reduce the heat transfer downward under the condition of stable layer; $v_{e}\left(\mathrm{~m}^{2} / \mathrm{s}\right)$ is the sum of the molecular viscosity coefficient $v$ and the turbulent eddy viscosity coefficient $v_{t}, v_{t}=C_{\mu} \frac{k^{2}}{\varepsilon} ; u, w(\mathrm{~m} / \mathrm{s})$ are the longitudinal and vertical flow velocities, respectively; $p$ is the pressure; $T\left({ }^{\circ} \mathrm{C}\right)$ is the water temperature; $B(\mathrm{~m})$ is the river width; $k$ is the turbulent kinetic energy; $\varepsilon$ is the dissipation rate of turbulent kinetic energy; $\sigma_{k}, \sigma_{\varepsilon}$ are the Prandtl number of the turbulent kinetic energy and the dissipation rate, generally 1.0 and 1.3, respectively. Other model constants: values of $C_{\mu}, C_{\varepsilon 1}, C_{\varepsilon 2}$ are $0.09,1.44$ and 1.92 , respectively.

(3) 2-dimensional water temperature equation: It is used to simulate the convection and diffusion of the water temperature scalars in the flow field.

$$
\begin{aligned}
& \frac{\partial}{\partial t}(B T)+u \frac{\partial}{\partial x}(B T)+w \frac{\partial}{\partial z}(B T) \\
= & \frac{\partial}{\partial x}\left(\frac{B v_{e}}{\sigma_{T}} \frac{\partial T}{\partial x}\right)+\frac{\partial}{\partial z}\left(\frac{B v_{e}}{\sigma_{T}} \frac{\partial T}{\partial z}\right)+\frac{1}{\rho C_{p}} \frac{\partial B \varphi_{z}}{\partial z},
\end{aligned}
$$

where $\sigma_{T}$ is the temperature Prandtl number and the value is $0.9 ; C_{p}\left(\mathrm{~J}\left(\mathrm{~kg}{ }^{\circ} \mathrm{C}\right)\right)$ is the specific heat of water; $\phi_{z}\left(\mathrm{~W} / \mathrm{m}^{2}\right)$ is the solar radiation flux through the $Z$ plane.

\subsubsection{Boundary condition}

(1) Free water surface: Calculate the heat flux coming from solar short-wave radiation, pure long-wave radiation, long-wave water surface returned radiation, water surface evaporation, heat conduction, etc. that pass into water through the surface, and use the result as the free surface boundary condition of the water temperature equation. Meanwhile, assume the vertical flow velocity of the free water surface to be zero and apply the rigid-lid assumption.

(2) Upstream inlets boundary: Use the measured water temperature in the end part of the reservoir as the water temperature condition of the reservoir inlets boundary. The velocity is assumed to be the vertical average speed, and the turbulent kinetic energy. The dissipation rate can be calculated approximately according to the inflow velocity.

(3) Outlets and solid walls: Assume that the flow in the outlet section is fully developed turbulence, and that the plane between reservoir bottom and dam body surface is adiabatic boundary without slide.

\subsubsection{Discrete solution and numerical solution of the equa- tions}

(1) Use finite volume method and hybrid scheme to discretize the differential equations. Use SIMPLE algorithm to solve difference equations and use staggered mesh to avoid the checkerboard type nonuniform pressure field.
(2) Use strong coupling method to solve the hydrodynamic equations and water temperature equations. At each time step, we first solve the $u, w$ momentum equations and the $k, \varepsilon$ equations, and then solve the water temperature equation. After that, the result water temperature value will be used to revise the source item in the $w, k$ equations, and then recalculate these hydrodynamic equations until the error of each equation is less than the allowable value.

\subsubsection{Model verification}

We choose the Ertan reservoir built in the downstream Yalong River as an analogue object, and observe the water temperature prototype in the whole reservoir. This observation data are used to verify the mathematical model and it can also provide analog reference data for the rationality analysis of the result.

The comparative results indicate that the calculation results and the measured values show no difference in the variation tendency along the river and the vertical water temperature structure. In the aspects of vertical water temperature distribution in front of the dam, variation of the surface thermocline, and low-temperature layer at the bottom, the simulation result of the 2-dimensional water temperature elevation model is comparatively identical to the measured prototype data. So it is feasible to choose 2-dimensional water temperature mathematical model as a forecast model of the temperature condition in the Jinping-I reservoir.

\subsection{The forecasting result of water temperature in the Jinping-I reservoir}

\subsubsection{The calculation condition}

The forecasting research is based on the representative normal flow year, and the inflow water temperature and weather condition applied in the research are the averages for previous years, where the single-layer inlets program is set to be calculation condition 1 and the three-level stoplog gates program to be calculation condition 2 .

\subsubsection{Forecasting result and analysis of the calculation condition 1}

Under the conditions of normal flow year, the single-layer inlets program, average inflow temperature and average weather condition for previous years (calculation condition 1) in the Jinping-I hydropower station, the reservoir discharged water temperature, surface water temperature, bottom water temperature, dam site natural water temperature and air temperature process during year are compared in Figure 2. The forecasting result indicates that the water temperature in the reservoir is in stratification status throughout the year and the delay of it is obvious. Compared to the temperature before the dam was built, the discharged water temperature was lower during March to June, and the biggest temperature difference was $2.3^{\circ} \mathrm{C}$, appearing in April. 


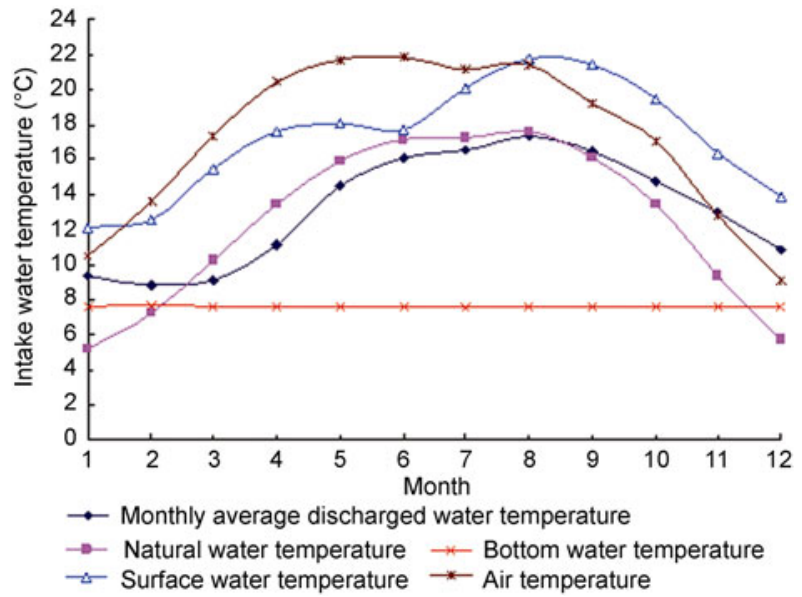

Figure 2 The monthly average discharged water temperatures, surface water temperatures, bottom water temperatures, dam site natural water temperatures and air temperatures in the Jinping-I hydropower station (calculation condition 1).

\subsubsection{Forecasting result and analysis of the calculation condition 2}

Under the conditions of normal flow year, three-layer stoplog gates program, average inflow water temperature and average weather condition for previous years (calculation condition 2) in the Jinping-I hydropower station, the reservoir discharged water temperature, surface water temperature, bottom water temperature, dam site natural water temperature and air temperature process during the year are compared in Figure 3. We can figure out that the bottom water temperature is stable throughout the year, retaining at $7.6^{\circ} \mathrm{C}$. The delay of the discharged water temperature is still obvious. During March to June, the discharged water temperature is a little higher and gets gradually closer to the natural water temperature at the corresponding periods.

\section{Research on the model test}

The actual effect of the stoplog gates multi-level intake is determined by the velocity field and the water temperature field near the inlets. In terms of dimensionality of research, this is a typical 3-dimensional problem, and it is difficult to really achieve the coupling of water temperature, density and flow field in the numerical simulation of the reservoir multi-level intake. To better simulate the distributions of velocity field and the water temperature field near the dam, we have conducted a research on the model test [11]. Firstly, a water temperature physical model was set up according to the hydraulic boundary conditions of the reservoir and the constructions. The vertical water temperature distribution in the prototype reservoir was simulated by the method of continuous layered heating according to the water temperature numerical simulation result, to achieve the synchronous simulation of the water temperature field and the velocity

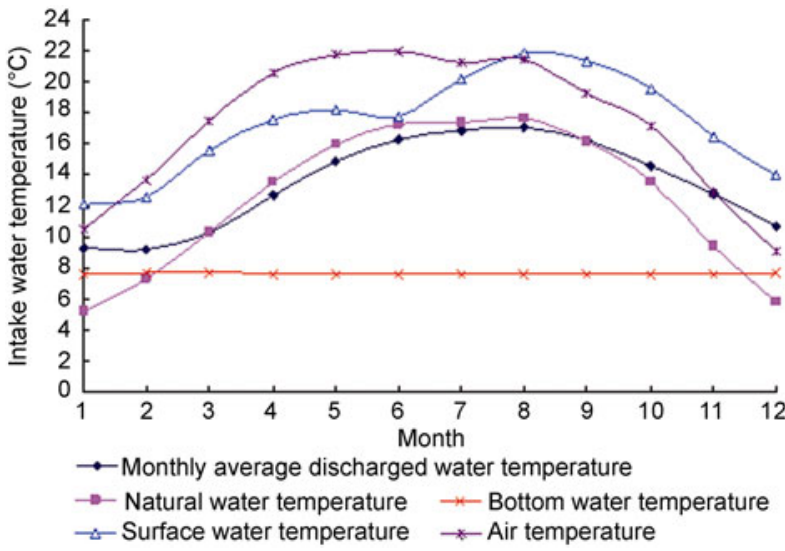

Figure 3 The monthly average discharged water temperatures, surface water temperatures, bottom water temperatures, dam site natural water temperatures and air temperatures in the Jinping-I hydropower station (calculation condition 2).

field. Then, under the condition of the flow and the water temperature field being relatively stable, we measured the discharged water temperature in the inlets corresponding to different stoplog gates heights, and extracted the quantitative research result.

\subsection{Model design}

Model design follows the gravity similarity law and the buoyancy similarity principle, uses the normal model with scale 1:150, and sets the bottom temperature as the ground temperature to convert the result of warming model test into the prototype value. It is a 3-D entity model and the simulation covers the range from the power station water inlets to the site $1.5 \mathrm{~km}$ away in the upstream. The detailed arrangement is shown in Figure 4.

\subsection{Test working condition}

The tests are focused on the normal flow year. As shown in Table 1, the research conditions of the water temperature tests each month are calculated according to the designed reservoir operation mode in the normal flow year.

\subsection{Analysis of the test result}

5.3.1 Argumentation of the reservoir flow field - water temperature control boundary

The research tests set the inflow boundary and the thermal stratification control boundary at the site $1500 \mathrm{~m}$ away in the upstream, and set 4 water temperature monitoring sections in the site $80 \mathrm{~m}$ in front of the inlets (C.S.4 section), the site $300 \mathrm{~m}$ away in the upstream (C.S.3 section), the site $675 \mathrm{~m}$ away in the upstream (C.S.2 section) and the site $1050 \mathrm{~m}$ away in the upstream (C.S.1 section). During the tests, the changes of water temperature were under the 


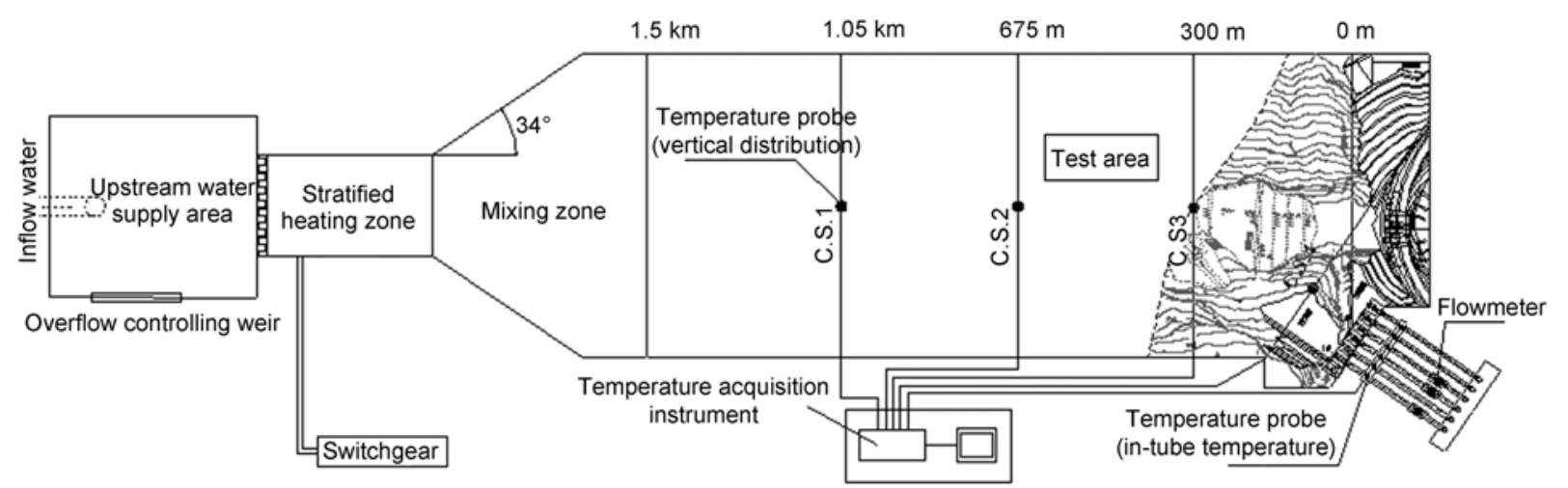

Figure 4 The arrangement diagram of the water temperature model.

Table 1 Research working conditions of the water temperature tests of a normal flow year

\begin{tabular}{|c|c|c|c|c|c|c|c|c|}
\hline Month & $\begin{array}{l}\text { Water level } \\
\text { in the } \\
\text { upstream }\end{array}$ & $\begin{array}{l}\text { Operation mode of } \\
\text { the stoplog gates }\end{array}$ & $\begin{array}{l}\text { Output power } \\
(\times 104 \mathrm{~kW})\end{array}$ & $\begin{array}{l}\text { Units } \\
\text { number }\end{array}$ & $\begin{array}{c}\text { Temperature in the } \\
\text { surface of reservoir } \\
T_{\mathrm{s}}\left({ }^{\circ} \mathrm{C}\right)\end{array}$ & $\begin{array}{c}\text { Temperature at the } \\
\text { bottom of reservoir } \\
T_{\mathrm{b}}\left({ }^{\circ} \mathrm{C}\right)\end{array}$ & $\begin{array}{c}\text { Discharged tem- } \\
\text { perature } \\
\text { (estimate) } T_{\mathrm{o}}\left({ }^{\circ} \mathrm{C}\right) \\
\end{array}$ & $\begin{array}{c}\text { Heating power } \\
\text { of the model } \\
(\mathrm{kW})\end{array}$ \\
\hline 1 & 1870.91 & $0 / 14 /(14+14) /(14+14+7)$ & 120.00 & 2 & 12.1 & 7.9 & 9.2 & 22 \\
\hline 2 & 1858.41 & $0 / 14 /(14+14) /(14+14+7)$ & 120.00 & 2 & 13.2 & 7.9 & 9.1 & 21 \\
\hline 3 & 1844.60 & $0 / 14 /(14+14) /(14+14+7)$ & 108.59 & 2 & 15.3 & 7.9 & 10.1 & 38 \\
\hline 4 & 1830.76 & $0 / 14 /(14+14) /(14+14+7)$ & 108.59 & 2 & 19.0 & 7.9 & 12.8 & 84 \\
\hline 6 & 1804.70 & 0 & 108.59 & 2 & 18.0 & 7.9 & 16.2 & 142 \\
\hline 7 & 1871.73 & $0 / 14 /(14+14) /(14+14+7)$ & 360.00 & 6 & 22.5 & 7.9 & 16.8 & 458 \\
\hline 8 & 1880.00 & $0 / 14 /(14+14) /(14+14+7)$ & 360.00 & 6 & 23.0 & 7.8 & 16.9 & 468 \\
\hline 9 & 1800.00 & $0 / 14 /(14+14) /(14+14+7)$ & 360.00 & 6 & 21.6 & 7.8 & 16.2 & 432 \\
\hline 10 & 1880.00 & $0 / 14 /(14+14) /(14+14+7)$ & 256.43 & 4 & 19.4 & 7.8 & 14.6 & 233 \\
\hline 11 & 1880.00 & $0 / 14 /(14+14) /(14+14+7)$ & 135.49 & 2 & 16.7 & 7.8 & 12.7 & 95 \\
\hline
\end{tabular}

real-time monitoring. The tests indicates that under the condition of operating inlets stoplog gates every month, the water temperature distributions in section C.S.3 and section C.S.4 are different with each other, but the vertical water temperature distributions in section C.S. 1 and section C.S.2 are similar. This means that the water temperature field is influenced by the dragging effect only in the zone between 250 and $500 \mathrm{~m}$ in front of the dam when the inlets are operating. Meanwhile, the velocity distributions in the tests indicate that the influence boundary of the velocity field near the inlets is between 230 and $600 \mathrm{~m}$. Therefore, the position of the reservoir flow field-water temperature boundary should be the larger one of the two values mentioned above. In conclusion, the water temperature-velocity boundary set in the model design is acceptable.

\subsubsection{Operating effect analysis of the inlets stoplog gates}

Shown in Figures 5 and 6 is the variation law of the intake water temperature corresponding to different heights of the stoplog gates in the inlet side hole (hole \#1) and central hole (hole \#4) obtained in the tests, where the relative tempera

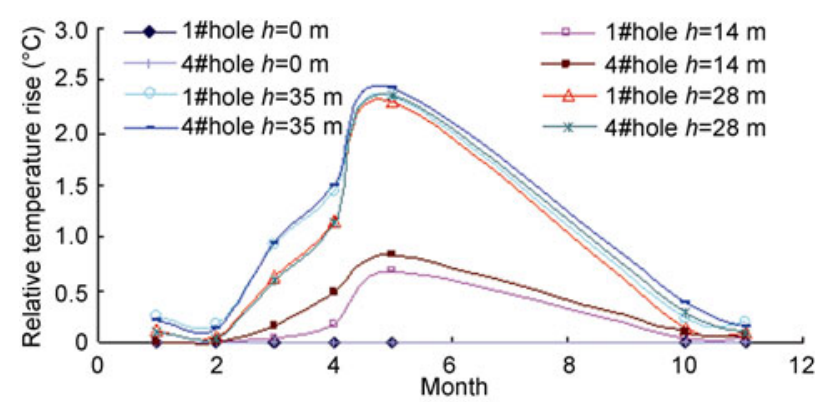

Figure 5 The relative temperature rises caused by the stoplog gates holes $\# 1$ and \#4.

ture rise means the water temperature growth extent after setting the stoplog gates when compared to the single-level intake (without stoplog gates).

The tests indicate that the effect of withdrawing the surface warm water of multi-level intake inlets is obviously better during March to May. As the height of the stoplog gates increases, the intake water temperature would also rise. When the 3 gate leaves are used to retain water, the tem- 


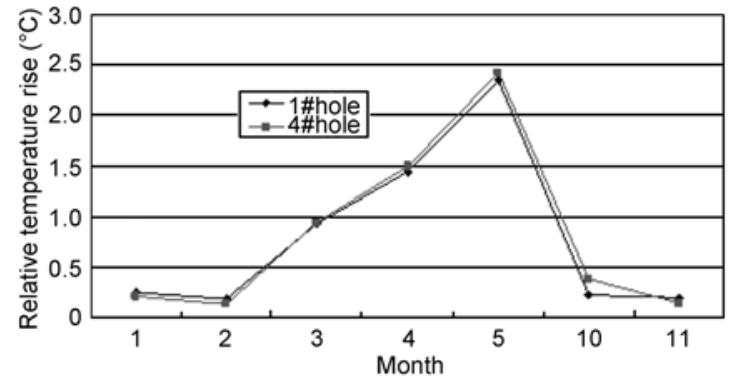

Figure 6 The schematic diagram of the relative temperature rises in inlets \#1 and \#4 (using 3 gate leaves to retain water).

perature rise caused by the stoplog gates can be $1.0-2.5^{\circ} \mathrm{C}$.

\subsubsection{Analysis of the inlets intake water temperature each month}

Shown in Figures 7 and 8 is the comparison month by month between the discharged water temperature of inlets \#1 and \#4 obtained in the tests and the natural dam site water temperature. We can see that the discharged water temperature of the single-level intake was lower than the natural temperature by $1.5-2.4^{\circ} \mathrm{C}$ during March to May. After the stoplog gates are installed, the discharged water temperature is obviously getting higher and becomes closer to the natural water temperature at the corresponding periods. In the period of June to September, because of the increasing solar radiation and the gradual water storage after flood, the water temperature in the reservoir keeps rising, but still

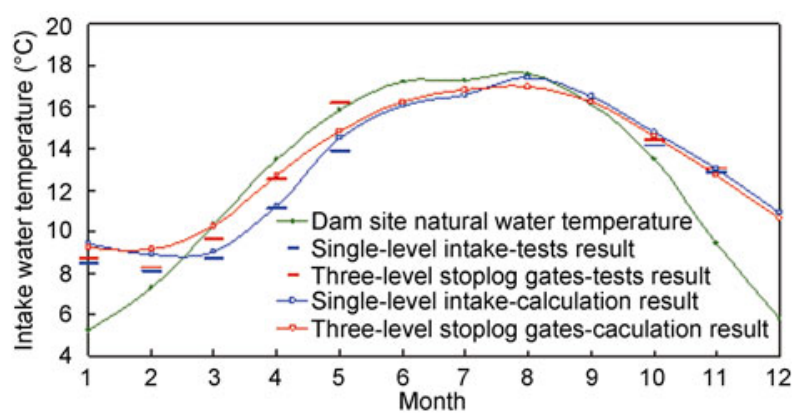

Figure 7 The water temperature variation in intake hole \#1 under the conditions of single-level intake and 3-level stoplog gates intake.

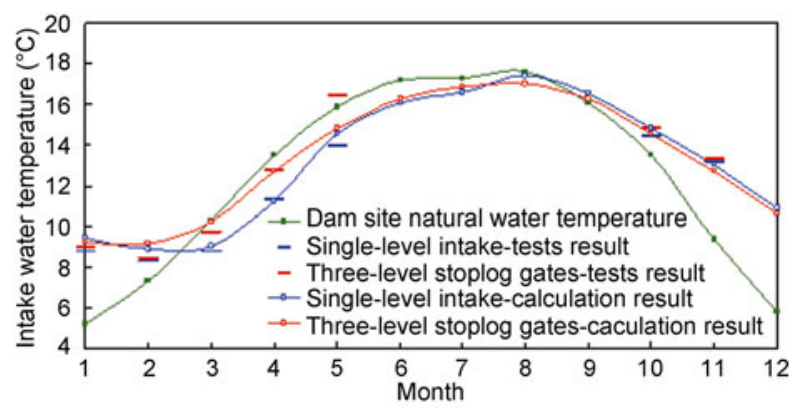

Figure 8 The water temperature variation in intake hole \#4 under the conditions of single-level intake and 3-level stoplog gates intake. a little lower than the natural water temperature. To make the discharged water temperature gets closer to the natural water, we can further raise the height of the stoplog gates. In the period of October to February in the next year, the warming effect caused by operating the stoplog gates is not obvious since the water level in the reservoir is getting higher and higher. But the temperature in the reservoir is high enough and evenly distributes at that time. Under the condition of single-level intake, the temperature has already been $1-3.5^{\circ} \mathrm{C}$ higher than the natural water temperature, so the stoplog gates need not to be used.

\section{Comparative analysis}

By analyzing the mathematical model calculation and the water temperature model tests result, we know that the discharged water temperatures in such two models follow the similar basic law. The discharged water temperature of the three-level stoplog gates program is closer to the natural river temperature than that of the single-level intake. After the multi-level intake measure is utilized, the calculation using the mathematical model indicates that the water temperature of the three-level stoplog gates program is $1.0^{\circ} \mathrm{C}$ higher than that of the single-level intake program in the warming period between March and May. The water temperature model tests show that the intake temperature rise caused by operating the stoplog gates can reach $1.0-2.5^{\circ} \mathrm{C}$. Compared to the situation of single-level intake, the discharged water temperature rises efficiently and is getting closer to the natural water temperature at the corresponding periods. Therefore, both the two methods utilized in this research verify the efficiency of the withdrawing surface warm water from the stoplog gates inlets in the Jinping-I hydropower project. Meanwhile, the physical model tests which are based on the result of the water temperature numerical simulation also verify the feasibility and reliability of adopting the 2-dimensional water temperature elevation model to simulate the water temperature in this research.

\section{Conclusion}

(1) Under the condition of the water temperature difference between the epilimnion and hypolimnion is determinate, the intake effect of withdrawing surface water by stoplog-type multi-level intake method is closely related to the water head above the stoplog gates: When the reservoir water level is high, the water head above the stoplog gates is big and the intake effect of the single-level intake shows little difference with that of the multi-level stoplog gates program; when the reservoir water level is low, the water head above the stoplog gates is small and the multi-level stoplog gates program can withdraw the surface warm water easier, and reduce the impact on the fish in the downstream 
from the discharged cold water.

(2) In the aspect of the variation situation of the discharged water temperature, in the period of March to June, the fish reproduction season which we have paid the most attention to, the arrangement program of the three-level stoplog gates intake can make the discharged water temperature closer to the natural water temperature to help the fish reproduction and the recovery of the ecosystem in the downstream, so this design is reasonable.

(3) According to the result of the water temperature physical tests, the discharged temperature from October to February in the next year is higher than the natural water temperature, so there is no need to use the stoplog gates. For this reason, the operating schedule program of the stoplog gates can be optimized.

(4) This research has combined the measures of numerical simulation and physical model test, which are complementary and can confirm each other, to fully verify the operating effect of the multi-level intake. It can provide technical reference for the solutions of similar problems in the future and it also has important engineering significance on the research of water temperature in large deep reservoirs.

This work was supported by the National Natural Science Foundation of China and EHDC Yalong River Joint Research Foundation of Hydropower Development Project (Grant No. 50639070).

1 Yang Z J, Liu D F, Ji D B, et al. Influence of the impounding process of the Three Gorges Reservoir up to water level $172.5 \mathrm{~m}$ on water eutrophication in the Xiangxi Bay. Sci China Tech Sci, 2010, 53(4): 1114-1125

2 Li R, Li J, Li K F, et al. Prediction for supersaturated total dissolved gas in high-dam hydropower projects. Sci China Ser E-Tech Sci, 2009, 39(12): 2001-2006

3 Vermeye T B. An overview of the design concept and hydraulic modeling of the Glen Canyon dam Multi-level intake structur. Proceedings of Waterpower'99 Conference. Las Vegas, July 6-9, 1999

4 Du X H, Yu W Q, Rui J L. Hydropower ecological practice - multi-level water intake structure. Water Power, 2008, 34(12): 28-32

5 Du X H. Analysis of design and operation of selective withdrawal modifications of Hungry Horse Dam. Water Power, 2008, 34(3): 17-19

6 Vermeyen T B. First year performance of the Shasta Dam temperature control device. Exploring our new frontiers, the best of Hydro Vision 98, Reno, CA, July 28-31, 1998

7 Chang L, Zong X, Zhang L. The water temperature analysis and prediction of Guang Zhao hydropower station reservoir and the multi-level intake measure. Design Hydropower Station, 2007, 23(3): $30-32,51$

8 Gao X P, Chen H, Wang A R, et al. Experimental study on temperature of water released from the multi-level intake of Nuozhadu hydropower station. J Hydroelectr Eng, 2010, 29(3): 126-131

9 You X, Tang B H, Zhang J X, et al. The influence on the flow and structural safety by the stoplog gates multi-level intake structure of the Jinping-I hydropower project. Adv Sci Technol Water Res, 2010, 30(4): 46-50

10 Deng Y, Li J, Xu W L, et al. Research on the multi-level intake water temperature of the Jinping-I hydropower project in the Yalong River. Technial Report, Sichuan University, 2006. 11

11 Sun S K, Liu H T, Wang X S, et al. Research on the multi-level intake inlets water temperature model test of the Jinping-I hydropower project in the Yalong River. Technial Report, China Institute of Water Resources and Hydropower Research, 2010. 6 